\title{
On the Journal of Plant Research in the Year 2012
}

\author{
Hirokazu Tsukaya
}

Published online: 7 December 2012

(C) The Botanical Society of Japan and Springer Japan 2012

Last year, 2012, was the fourth year for me as the Editorin-Chief of the Journal of Plant Research (JPR) and was originally planned to be the final year for me to pursue this honored role. To our delight, the year 2012 recorded the highest impact factor (IF) for the JPR, which was 1.746. As shown in Fig. 1, the IF of JPR steadily increased year by year, without any indication of slowing down. This trend was established during the tenure of Prof. K. Nishitani, the Editor-in-Chief from 2005 to 2008, and I just have kept the growth going after succeeding him in the role of Editor-inChief. It was an easy task, since JPR seemed to grow very naturally. This growth is thanks to the efforts by authors, reviewers, editors, the publisher, and all of you who read the journal. JPR now is one of the most important international journals that cover general basic plant science, although of course JPR already had been chosen as one of the top 100 journals in biology and medicine over the last 100 years in 2009 (http://dbiosla.org/publications/resources/ dbio100.html, Tsukaya 2009). Now ca. 500 manuscripts are submitted to JPR annually, and the acceptance ratio is ca. $15 \%$. Submissions from Japan account for only onefourth of them; the others are from various countries in Asia, Europe, North America, Africa, and other areas.

The Botanical Society of Japan (BSJ), the parent society from which the JPR is published, is also growing well now. Last year, on 2 July 2012, BSJ became a Public Interest Corporation (PIC). This means that BSJ is officially recognized as a society with a basically charitable corporation form, its charitable status legally recognized by the Public

H. Tsukaya $(\bowtie)$

Graduate School of Science, The University of Tokyo, Science Building \#2 7-3-1 Hongo, Bunkyo-ku, Tokyo 113-0033, Japan

e-mail: jpreic@biol.s.u-tokyo.ac.jp
Interest Corporation Commission among the General Incorporated Associations and Foundations in Japan. BSJ was allowed to be a PIC by virtue of its academic and scientific promotion activity for public interest purposes (see http://www.kohokyo.or.jp/english/Charitable\%20 organizations\%20in\%20Japan/Guidance.html for the PIC legal scheme).

Due to this change in the recognition of BSJ as a public interest corporation, the timing of the replacement of the Editor-in-Chief has been changed: formerly it was when 1 year ended and the next one began, but now BSJ must make the change after a formal vote in March. The next formal vote to determine the new Editor-in-Chief will be held in March 2013, and I will continue to work as the Editor-in-Chief until the voting is carried out. My term thus is prolonged for 2 months beyond the previously planned full 4 years from January 2009. The duration of the terms for Editors and Editorial Board members has not changed, however, even after the above-described change in the system, so as you may have noticed in the list printed in this issue of the journal, some new members already have joined us from this January. I believe that the new editorial team will strongly support the new Editor-in-Chief, who will be announced in the coming issue published in May 2013.

Finally, as a demonstration of the typical level of our publication, I am pleased to state that the two following papers have won the Journal of Plant Research (JPR) Best Paper Award 2012:

1. Hidenori Tsuboi and Masamitsu Wada (2011) Chloroplasts can move in any direction to avoid strong light. Journal of Plant Research 124: 201-210.

2. Masao Nishimura and Hiroaki Setoguchi (2011) Homogeneous genetic structure and variation in tree architecture of Larix kaempferi along altitudinal gradients on Mt. Fuji. Journal of Plant Research 124: 253-263. 


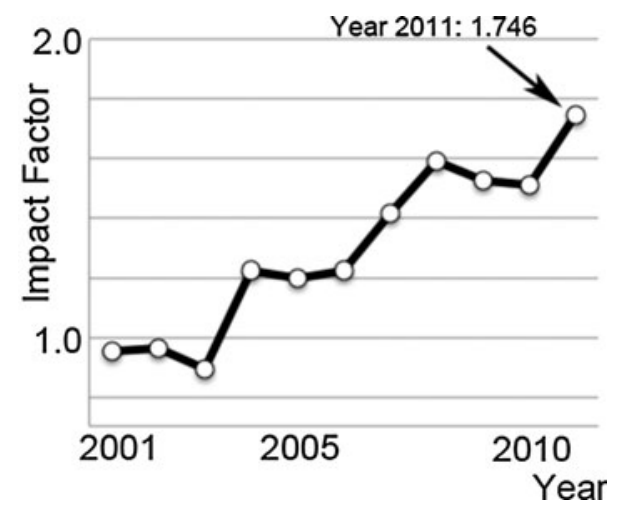

Fig. 1 Impact factor trend of the Journal of Plant Research from 2001 to 2011. Data are based on Journal Citation Reports ${ }^{\circledR}$ in Web of Science (Thomson Reuters)

These award-winning works were selected from all the original papers published in the Journal of Plant Research in 2011 by votes of the Editorial Board members according to the JPR Awards Selection Procedure. Tsuboi and Wada (2011) reported the nature of chloroplast movement against a microbeam of strong blue light in Adiantum capillusveneris L. and Arabidopsis thaliana (L.) Henh. Nishimura and Setoguchi (2011) reported, on the other hand, the homogeneous genetic structure of Larix kaempferi on a young mountain, Mt. Fuji, where this species is dominant and shows wide morphological variation.

In addition to the above-mentioned awards, the winner of the Most-Cited Paper Award is selected from all the papers published in 2009 by reference to the ISI database. That award was won by the following paper:

- Hiroki Miwa, Atsuko Kinoshita, Hiroo Fukuda and Shinichiro Sawa (2009) Plant meristems: CLAVATA3/ $E S R$-related signaling in the shoot apical meristem and the root apical meristem. Journal of Plant Research 122: 31-39.
This review article concisely summarized the understandings of genetic regulation systems of shoot and root apical meristems, in particular focusing on the WUSCHEL-CLAVATA system. This topic is now very hot; the authors have been pioneers in this research field; and this review article had been cited 17 times from its publication to the end of 2011.

As seen above, the two Best Paper awardees are in the fields of photobiology and geobotany, respectively, and the Most-Cited Paper awardee is in the field of molecular developmental genetics. As clearly shown by the above three articles, JPR has published excellent papers covering a wide range of basic plant sciences from physiology, geobotany, taxonomy, anatomy, and ecology, to molecular genetics. By continuing to publish good papers and reviews with great impact, JPR will contribute significantly to the plant science field.

Hirokazu Tsukaya

Editor-in-Chief, Journal of Plant Research

\section{References}

Miwa H, Kinoshita A, Fukuda H, Sawa S (2009) Plant meristems: CLAVATA3/ESR-related signaling in the shoot apical meristem and the root apical meristem. J Plant Res 122:31-39

Nishimura M, Setoguchi H (2011) Homogeneous genetic structure and variation in tree architecture of Larix kaempferi along altitudinal gradients on Mt. Fuji. J Plant Res 124:253-263

Tsuboi H, Wada M (2011) Chloroplasts can move in any direction to avoid strong light. J Plant Res 124:201-210

Tsukaya H (2009) Journal of Plant Research chosen as one of the top 100 journals in biology and medicine over the last 100 years. J Plant Res 122:353-354 